\title{
Epizootological situation with demodicosis infestation of dogs in the Central Chernozem region of the Russian Federation
}

\author{
Elena O. Vozgorkova \\ Associate professor of the Department of Veterinary-Sanitary \\ Expertise, Epizootology and Parasitology \\ Voronezh State Agricultural University \\ 1 Michurina Street, Voronezh, Russian Federation \\ lena14022010@mail.ru
}

\author{
Nadezhda S. Bespalova \\ Professor of the Department of Veterinary-Sanitary Expertise, \\ Epizootology and Parasitology \\ Voronezh State Agricultural University \\ 1 Michurina Street, Voronezh, Russian Federation \\ Nadezh.bespalova2014@yandex.ru
}

\author{
Sergey N. Semyonov \\ Head of the Department of Veterinary-Sanitary Expertise, Epizootology and Parasitology \\ Voronezh State Agricultural University \\ 1 Michurina Street, Voronezh, Russian Federation \\ ss ramon@mail.ru
}

\begin{abstract}
The paper presents the study of epizootological situation with demodicosis infestation of dogs in the Central Chernozem region of the Russian Federation from 2010 to 2017. The retrospective and operational analysis of veterinary reports of public and private veterinary institutions was carried out. In total, the survey data on 1970 dogs belonging to private owners, doghouses, dog shelters, as well as on free-ranging dogs were obtained. The study was based on the detection of fixed itch mites through the translucency of scabs in glycerol according to Vaida technique (Vozgorkova E.O., Bespalova N.S. 2014) using Levenhuk T510 NG digital camera and ToupView software. Statistical processing was carried out in BioStat 2009 and SPSS Statistics 17.0.
\end{abstract}

The study revealed that in Voronezh region of the Central Chernozem area of the Russian Federation the prevalence $(P)$ of dogs with demodicosis on average makes $31.5 \%$ (621 dogs). During autumn and spring, 32\% (199 dogs) and $28 \%(174 \mathrm{dogs})$ cases respectively were registered. The prevalence level during winter and summer made $21 \%$ and $19 \%$ (130 and 118 dogs respectively).

The study of epizootological situation showed the highest level of dogs from 2 months to 1.5 years old affected by demodicosis $67 \%(416$ dogs $)$. The disease was diagnosed in $27 \%$ cases $(168$ dogs) of affected dogs from 1.5 to 4 years old. For animals above 4 years old the disease was diagnosed in $6 \%$ cases $(37 \mathrm{dogs})$.

The assessment of demodicosis distribution among dogs of different breeds revealed high level of invasion among French bulldogs - 25\% (155 dogs) and English bulldogs - 19\% (118 dogs). Quite often, the disease was recorded among badger dogs - 9\% (56 dogs) and Staffordshire Terriers $-7 \%$ (43 dogs). Among nonpedigree free-ranging dogs the demodicosis was detected in $15 \%$ cases ( 93 dogs).

The study showed what demodicosis is more often diagnosed for female $-51 \%(317 \mathrm{dogs})$ rather than for male dogs $-49 \%(304$ dogs).

Canine demodicosis is a widespread invasion in the Central Chernozem region of the Russian Federation characterized by moderate seasonal dynamics. It is typical for pedigree animals aged from 2 months to 1.5 years, mostly for French and English bulldogs kept in apartments. It is only recorded for free-ranging dogs in $15 \%$ cases.

Keywords- dog; demodicosis; infestation; epizootological situation, Russian Federation

\section{INTRODUCTION}

Currently, pet breeding and care in various regions of Russia requires additional knowledge on various issues. In recent decades, dogs living in urban conditions are severely exposed to disturbing factors, such as multiple stressful situations, constantly deteriorating environment, poor quality of finished feed, uncontrolled breeding, etc. (Shapovalova O., Glamazdin I.G., Sysoyeva N.Yu., 2014; Belova S., 2011).

The problem of demodicosis in dogs has always been urgent for veterinary experts and has gained a particular importance due to increased number of dogs living in limited territories. The data of many authors confirm wide distribution of demodicosis in the Russian Federation (Stolbova O.A., 2017; Moskvina T.V., Zheleznova L.V., 2015; Elizarov A.P., 2015, et al.). Some of them indicate the tendency towards the distribution of invasion in urban lands (Stolbova O.A., 2017; Yarovaya N.V., 2010). This is caused by the lack of due veterinary monitoring over the population of dogs, uncontrolled use of veterinary drugs, unregulated breeding of dogs prone to this parasitic disease, as well as considerable demand for working dogs (Rottweilers, German shepherds, etc.) and their excessive reproduction regardless the principles of controlled breeding and selection of diseased animals (Belova S., 2011; Izdebska J.N., Fryderyk S., 2011).

According to Elizarov A.P., the rate of demodicosis in dogs, i.e. population boundaries of its epizootic manifestation are different and depend on the activation of factors of the infectious agent transfer to infestation or are in inverse 
dependence on the destruction level of a specific mechanism of infecting agent migration among the population of dogs living in a certain territory (Elizarov A.P., 2015).

In this respect, the study of epizootological situation and monitoring of demodicosis in dogs in residential areas is particularly important to develop the efficient action plan on disease prevention

\section{MATERIALS AND METHODS}

The study was carried out from 2010 to 2017 in veterinary institutions of Voronezh region.

The study of epizootological situation with demodicosis was based on the analysis of veterinary reports from private and state veterinary clinics, as well as examination data of 1970 dogs belonging to private owners, doghouses, dog shelters, as well as free-ranging dogs. Seasonal and age dynamics of demodicosis in dogs was determined by monthly analysis of statistical data over 7 years (2010-2017), as well as clinical and laboratory examination of animals getting to veterinary clinics.

The diagnosis was made taking into account the medical history, clinical findings and the results of microscopic study of deep skin scraping by applying the vegetable oil on the surface of the affected area. After 5 minutes of exposure, the skin was scrapped with a blunt scalpel surface until the capillary blood, lymph and follicle content was seen while the sentinel pile was strongly squeezed. The scrape was placed on a glass slide, glycerol solution was added and studied under the microscope using Levenhuk T510 NG digital camera and ToupView software (Bespalova N.S., Vozgorkova E.O., 2017)

\section{FINDINGS}

In total, 1970 dogs with skin-hair pathology were treated during 2010-2017 in veterinary clinics of various districts of Voronezh and adjacent territories. Demodicosis was diagnosed for 621 animals. The prevalence $(\mathrm{P})$ made $31.5 \%$.

In 2010,212 dogs with symptoms of skin-hair pathology were examined. Demodicosis was diagnosed for 69 animals. The prevalence made $32.55 \%$.

In 2011, 262 dogs were diagnosed. Demodicosis was confirmed in 81 cases. The prevalence made $30.92 \%$.

In 2012, 287 dogs with symptoms of hypotrichosis and dermatitis were examined in veterinary clinics of Voronezh. During laboratory tests 88 animals were diagnosed with demodicosis. The prevalence made $30.66 \%$.

In 2013, 259 animals with clinical features of dermatosis were examined. Demodicosis was confirmed in 86 cases. The prevalence made $33.20 \%$.

In 2014, 305 dogs were diagnosed. Demodicosis was confirmed in 91 cases. The prevalence made $29.8 \%$.

In 2015 , demodicosis was confirmed in 84 cases. In total, 278 dogs were examined. The prevalence made $30.2 \%$.

In 2016, among 235 animals with skin-hair pathology features 77 were affected by Demodex mites. Thus, the prevalence made $32.8 \%$.
In 2017, data on examination of 132 dogs were obtained. Demodicosis was diagnosed in 45 cases. The prevalence made 34\% (Figure 1).

The statistical analysis was carried out against such indicators as seasonal, age, pedigree and gender specificity of infestation.

The study revealed the tendency towards the increase in the number of diseased dogs in autumn and spring. In autumn, 510 dogs with symptoms of skin-hair pathology were examined. Demodicosis was confirmed for 199 animals via laboratory diagnostics. The prevalence during this season made $32 \%$.

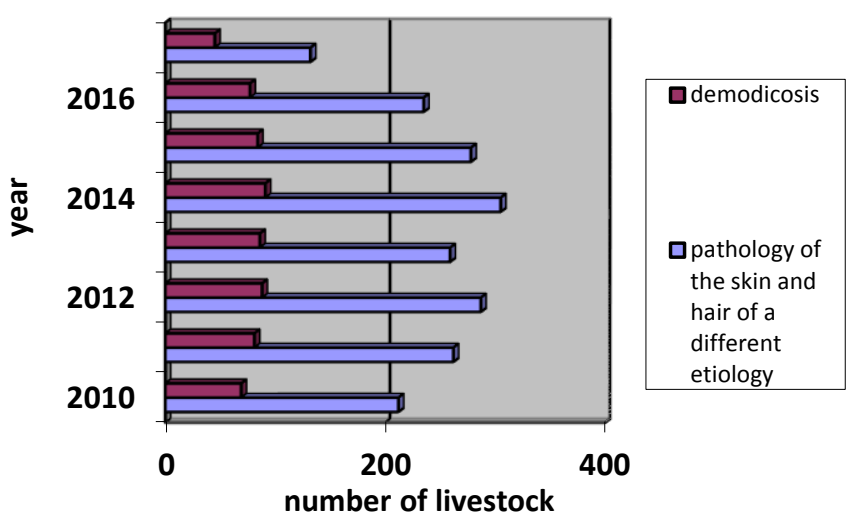

Fig. 1. Rate of canine demodicosis in the Central Chernozem region of the Russian Federation

In winter, 504 dogs with dermatitis of various etiology were treated in veterinary clinics. Demodicosis was diagnosed for 130 animals. The prevalence made $21 \%$.

In spring, 493 dogs were examined, Demodex mites were found in skin scrapes of 174 animals. The prevalence made $28 \%$.

In summer, 463 dogs with symptoms of skin pathology were examined. Demodicosis was confirmed for 118 animals. The prevalence made 19\% (Figure 2).

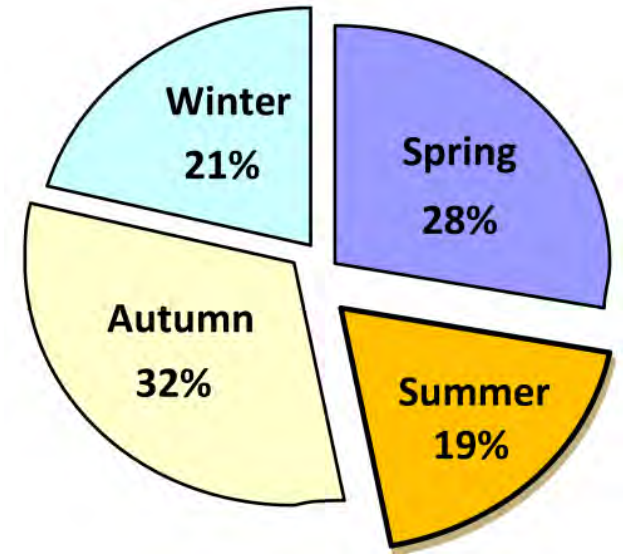

Fig. 2. Seasonal dynamics of canine demodicosis 
The susceptibility of dogs to demodicosis depending on age was established during the study. The majority of dogs affected by demodicosis were from 2 months to 1.5 years old -416 animals (67\%). Dogs aged from 1.5 to 4 years were less affected by demodicosis, which made $27 \%$ of animals with demodicosis (168 dogs). Demodicosis in animals above 4 years old was registered in 6\% cases (37 dogs) (Figure 3 ).

The analysis of demodicosis rate in dogs of various breeds demonstrates that acariasis is more typical for shorthaired animals with well-developed sebaceous glands - 410 dogs $(66 \%)$. However, many dog breeds and nonpedigree freeranging animals are subject to this disease).

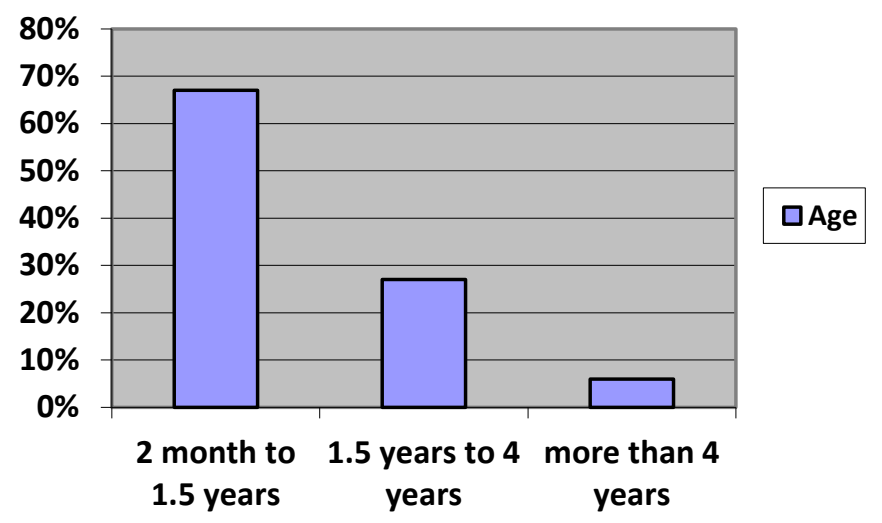

Fig. 3. Level of demodicosis infestation depending on dog age (\%)

More often demodicosis was diagnosed in French (155 dogs $-25 \%)$ and English (118 dogs - 19\%) bulldogs. Among other pedigree groups, high percentage of incidence was recorded among badger dogs - 9\% (56 cases) and Staffordshire terriers $7 \%$ (43 cases). A substantial proportion of the disease rate was recorded for nonpedigree free-ranging animals (93 dogs $-5 \%$ ). Rare cases of demodicosis were recorded for German shepherd, pug-dog, Rottweiler.

The study allowed diagnosing demodicosis in 317 female (prevalence - 51\%) and 304 male (prevalence - 49\%) dogs (Figure 4).

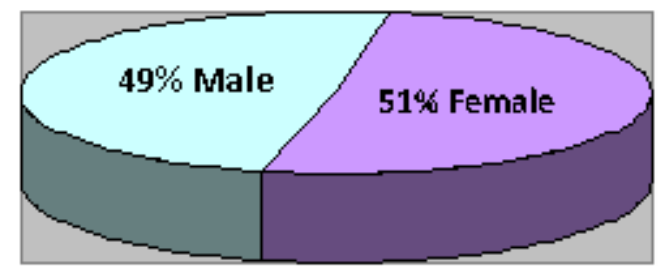

Fig. 4. Level of demodicosis infestation depending on dog gender

\section{DISCUSSION}

Demodicosis is not a rare phenomenon in veterinary and medical practice. Certain works of domestic and foreign authors are devoted to this matter (Syuch, 2004; Ozdemir M.H., Aksoy U., Sönmez E., Akisu C., Yorulmaz C., Hilal A., 2005; Yarovaya, 2010, Chornenka Z.H., 2017, et al.).
The study of epizootological situation with demodicosis infestation of dogs in the Central Chernozem region of the Russian Federation confirmed high prevalence of this disease $31.5 \%$. High rate of demodicosis in dogs is also recorded in Moscow - 37.1\% (N.V. Yarovaya, 2010), Tyumen - 41.2\% (O.A. Korotayeva, 2005), Krasnodar Krai - 46.8\% (N.N. Khrapay, 2001). In Ivanovo during 1997-2001 demodicosis was registered in $33.5 \%$ cases (Romensky V.I., 2001). In the urban land of the Lower Volga region canine demodicosis made $12.5 \%$ in nosological profile of invasive and infectious pathology of dogs (S.A. Vedeneyev, 2001).

In the Central Chernozem region of the Russian Federation canine demodicosis is characterized by moderate seasonal dynamics (Vozgorkova E.O., Bespalova N.S., 2014). The ratio of diseased animals is higher during the autumn season $(32 \%)$ and lower during other seasons of the year (19-28\%). In different regions of Russia these values are higher. According to N.V. Yarovaya (2010), in Moscow the peak of infection was recorded in autumn (51\%), in spring - the number of diseased animals was reduced to $31 \%$, in summer $-10 \%$, and in winter $-8 \%$ cases of demodicosis were registered. The study of O.A. Korotayeva (2005) demonstrates that the highest number of diseased animals was registered in summer $-38.6 \%$, in autumn $-21.5 \%$, in winter $-16.2 \%$ and in spring $-23.7 \%$. N.N. Khrapay (2001) indicates that canine demodicosis is diagnosed in $13.7 \%$ cases in winter, $20.9 \%$ - in spring, $36.1 \%$ - in summer, and $27.3 \%$ cases - in autumn.

According to some authors, the highest activity of human Demodex mites is recorded in spring and summer periods, which is attributed to increased exposure to sunlight, air temperature changes, immune and endocrine disorders. Despite the fact that the detection of mites is not linked to any season, earlier the incidence of patient visits to dermatovenerologic clinics for examination on Demodex spp was higher from March to October and decreased during winter thus resulting in statements on seasonal activity of these mites. According to Sirmays N.S. et al., there are no particular monthly differences in Demodex spp detection, but once the skin is prepared for examination (lack of hygienic measures in the morning before examination) it increases almost 2-2.5 times (Sirmays N.S., Abesadze G.A., Ustinov M.V., 2013).

The study also confirmed the dependence of the number of diseased animals on their age. The majority of diseased dogs were from 2 months to 1.5 years old, which made $67 \%$ of the total number of dogs having demodicosis. Demodicosis was registered in $27 \%$ cases among animals from 1.5 to 4 years old. Only $6 \%$ of dogs having demodicosis were above 4 years old (age group of animals from 4 to 13 years).

Age predisposition of animals to demodicosis is bound to the so-called 'immunologic holes'. This period is characterized by the reduction of natural host defenses in animals (normal exfoliation time and planned immunization), as well as stress due to change of the owner and habitat, physiological reorganization of animal organisms (Shustrova M.V., Arrestov VA., 2003; Kligman A.M., Christensen M.S., 2011; Ralf S. Mueller, 2012; Shapovalova O., Glamazdin I.G., Sysoyeva N.Yu., 2014, et al.). 
The given study correlates well with the data obtained by other authors. S.A. Vedeneyev (2001) recorded demodicosis among puppies of 6-12 month old in $39.5 \%$ cases, under 6month old - in $29.3 \%$ cases, from one to three years - in $21 \%$ cases. V.I. Romensky (2001) recorded the highest prevalence of demodicosis in animals aged 11-12 months - 59.6-65\%. The dogs aged 3-10 month showed the moderate degree of invasion $-14-47.6 \%$, and the dogs from 1.5 years and above -19.7 $38.9 \%$. Elizarov A.P. et al. (2015) points out that in Nizhny Novgorod young dogs from 6 to 12 month old (39.5\%) and puppies under 6 month old (29.3\%) are affected by demodicosis the most.

Many authors noted a certain dependence of canine demodicosis on hair type and length. According to O.A. Korotayeva (2005), demodicosis was detected in $51.1 \%$ cases among shorthaired dogs and in $48.9 \%$ cases - among longhaired ones. N.N. Khrapay (2001) also notes that shorthaired dogs are mostly subjected to demodicosis, which accounts to $53.7 \%$ cases. Elizarov A.P. (2015) also notes that the probability of demodicosis is much higher for smoothhaired dogs than for longhaired ones. At the same time high prevalence is registered by the author among bull terriers, English bulldogs and bullmastiffs. Similar data were also obtained by other authors (Stolbova O.A., 2017; Belova S., 2011; Kim L. Horne, 2010; Katayeva, Kostylyova, 2008, et al.).

The analysis of epizootic situation with demodicosis in dogs of various breeds demonstrates that demodicosis is more often recorded among shorthaired animals with well-developed sebaceous glands (66\% cases). Most often, the owners of French (25\%) and English bulldog (19\%) suffering from demodicosis appeal to veterinary clinics. High disease rate was noted in nonpedigree free-ranging dogs - 93 cases $(15 \%)$. These animals act as reservoirs and sources of invasion in urban lands having high density of dogs. Most likely, the high level of invasion among certain dog breeds is caused by their popularity among the population and uncontrolled breeding without considering their health status.

The study did not reveal clear gender prevalence of canine demodicosis, however this disease was more often diagnosed in female (51\%) and less for male dogs (49\%).

The obtained data correlates well with the study of other authors (Belova S., 2011; Tater K.C., Patterson A.C., 2008; Korotayeva, 2005, et al.).

However, according to S.A. Vedeneyev (2001), the demodicosis invasion was more often registered among males (62.4\%). Similar data were obtained by Elizarov A.P. (2015) regarding dogs in Nizhny Novgorod. On the contrary, the study of Yarovaya N.V. (2010) demonstrates that females are more susceptible to demodicosis $(65 \%)$ than males $(35 \%)$.

\section{CONCLUSIONS}

The study of epizootological situation with canine demodicosis in the Central Chernozem region of the Russian Federation allowed confirming high prevalence of this disease, which makes $31.5 \%$. In spring and autumn, the infestation falls within $28 \%$ and $32 \%$, in summer and winter it decreases to $19 \%$ and $21 \%$ respectively. Demodicosis is recorded for dogs aged from 2 months to 13 years. The highest prevalence is registered for dogs aged from 2 months to 1.5 years and makes $67 \%$. There is no clear gender prevalence of canine demodicosis. Demodicosis is diagnosed in $66 \%$ cases of shorthaired dogs, mainly French and English bulldogs (25 and 19\%) and in 34\% cases of longhaired dogs, including German shepherd $(6 \%$ cases), Bernese Mountain dog (4\%) and animals of other breeds. For nonpedigree free-ranging dogs, demodicosis is recorded in $15 \%$ cases, which indicates their importance in epizootology of this infestation.

Thus, the study confirms that the epizootological monitoring of demodicosis features among animals living in certain territories is one of the main functions of veterinary services.

Besides, it was established that the epizootic manifestation of infectious diseases has its own peculiarities depending on epizootic intensity, animal species, age, breed and many other factors.

\section{References}

[1] S. Belova, "Demodicosis in dogs - Demodicosis canum", VetPharma, Moscow: Medforum, 2011, pp. 28-33.

[2] N.S. Bespalova, E.O. Vozgorkova, "Acarology for veterinary physicians", S-P: Lan, 2017, p. 207.

[3] S.A. Vedeneyev, "Epizootological monitoring in case of canine demodicosis in urban land of Lower Volga region", Extended abstract of Cand. Sci. (Veterinary Science) Dissertation, Nizhny Novgorod, 2001, p. 24.

[4] E.O. Vozgorkova, N.S. Bespalova, "Demodicosis in dogs", Saarbrucken: Lap Lambert Academic publishing, 2014, p. 46.

[5] A.P. Elizarov, "Features of epizootic manifestation of demodicosis in pet carnivorous animals", Scientific notes of Bauman Kazan State Academy of Veterinary Medicine, Kazan, 2015, pp. 89-91.

[6] O.A Korotayeva, "Canine demodicosis in Tyumen: epizootology, biochemistry, immunology, therapy", extended abstract of Cand. Sci. (Biology) Dissertation, Tyumen, 2005, p. 23.

[7] T.V. Moskvina, L.V. Zheleznova, "Canine demodicosis in Vladivostok in 2014-2015", Veterinary pathology, Moscow: Veterinary consultant, 2015, pp. 31-37.

[8] R. S. Mueller, "Sarcoptic mange, demodicosis and otodectic mange in dogs", JSAP treatment methods, Russian edition, vol. 3, No. 1, 2012, pp. 50-52.

[9] V.I. Romensky, "Canine demodicosis in Ivanovo: epizootology, pathogenesis, clinical findings, treatment", extended abstract of Cand. Sci. (Veterinary Science) Dissertation, Ivanovo, 2001, p. 26.

[10] O.A. Stolbova, "Canine demodicosis in Northern Trans-Ural region, Theory and practice of fight against parasitic diseases", Moscow: AllRussian Research Institute of Fundamental and Applied Parasitology of Animals and Plants named after K.I. Scriabin, 2017, pp. 477-479.

[11] N.N. Khrapay, "Canine demodicosis in the Black Sea coast of Krasnodar Krai (epizootology, pathogenesis, control", extended abstract of Cand. Sci. (Veterinary Science) Dissertation, Moscow, 2001, p. 22.

[12] O. Shapovalova, I.G Glamazdin, N.Yu. Sysoyeva, "Pathogenesis of dermatitis of demodicosis etiology in dogs", Russian Journal of Parasitology, Moscow, 2014, pp. 40-43.

[13] M.V. Shustrova, V.A. Arestov, "Demodicosis in dogs - problems of diagnostics and treatment", Saint Petersubr: St. Petersburg Academy of Veterinary Medicine, 2003, p. 47.

[14] N.V. Yarovaya, "Epizootological monitoring in case of canine demodicosis in Moscow and development of combined therapy", extended abstract of Cand. Sci. (Veterinary Science) Dissertation, Moscow, 2010, p. 20. 
[15] Z.H. Chornenka, "Analysis of hormone-immune connections in patients with demodecosis", The unity of science, 2017, No. 1-2, pp. 148-153.

[16] J.N. Izdebska, S. Fryderyk, "Diversity of three species of the genus Demodex (Acari, Demodecidae) Parazitizing dogs in Poland", Polish. J. of Environ. Stud, 2011, vol. 20, No. 3, pp. 565-569.

[17] K. L. Horne, "Canine Demodicosis, Veterinary Technician, 2010, Retrieved from: http//vetlearn.com.
[18] A.M.Kligman, M.S. Christensen, "Demodex folliculorum: Requirements for Understanding Its Role in Human Skin Disease", Journal of Investigative Dermatology, 2011, No. 131, pp. 8-10.

[19] M.H. Ozdemir, U. Aksoy, E. Sönmez, C. Akisu, C. Yorulmaz, A. Hilal, "Prevalence of Demodex in health personnel working in the autopsy room", Am J Forensic Med Pathol, 2005, vol. 26, No. 1, pp. 18-23.

[20] K.C. Tater, A.C. Patterson, "Canine and feline demodecosis", Vet.Med., 2008, vol. 1, pp. 444-461. 